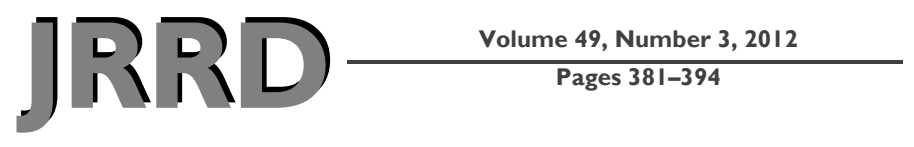

\title{
Impact of adding artificially generated alert sound to hybrid electric vehicles on their detectability by pedestrians who are blind
}

\author{
Dae Shik Kim, PhD; ${ }^{*}$ Robert Wall Emerson, PhD; ${ }^{1}$ Koorosh Naghshineh, PhD; ${ }^{2}$ Jay Pliskow, MS; $^{3}$ \\ Kyle Myers, $\mathbf{M S}^{2}$ \\ Departments of ${ }^{1}$ Blindness and Low Vision Studies and ${ }^{2}$ Mechanical and Aeronautical Engineering, Western Michigan \\ University, Kalamazoo, MI; ${ }^{3}$ Power Technologies Group, Dana Holding Corporation, Lisle, IL
}

\begin{abstract}
A repeated-measures design with block randomization was used for the study, in which 14 adults with visual impairments attempted to detect three different vehicles: a hybrid electric vehicle (HEV) with an artificially generated sound (Vehicle Sound for Pedestrians [VSP]), an HEV without the VSP, and a comparable internal combustion engine (ICE) vehicle. The VSP vehicle (mean $+/-$ standard deviation [SD] $=$ $38.3+/-14.8 \mathrm{~m}$ ) was detected at a significantly farther distance than the HEV (mean +/- SD = 27.5 +/- $11.5 \mathrm{~m}$ ), $t=4.823, p<$ 0.001 , but no significant difference existed between the VSP and ICE vehicles (mean $+/-\mathrm{SD}=34.5+/-14.3 \mathrm{~m}$ ), $t=1.787$, $p=0.10$. Despite the overall sound level difference between the two test sites (parking lot $=48.7 \mathrm{dBA}$, roadway $=55.1 \mathrm{dBA}$ ), no significant difference in detection distance between the test sites was observed, $F(1,13)=0.025, p=0.88$. No significant interaction was found between the vehicle type and test site, $F(1.31,16.98)=0.272, p=0.67$. The findings of the study may help us understand how adding an artificially generated sound to an HEV could affect some of the orientation and mobility tasks performed by blind pedestrians.
\end{abstract}

Key words: alert sound, blind, detectability, hybrid electric vehicle, orientation and mobility, pedestrian safety, quiet car, vehicle detection, Vehicle Sound for Pedestrian, visually impaired.

\section{INTRODUCTION}

Sound from vehicles is a critical source of information used for travel by pedestrians who are blind [1-2]. The acoustic characteristics of vehicle sounds as well as those of the environment seem to affect how well a given vehicle can be detected in different surroundings [3-6]. Given this, adding an artificially generated sound to a hybrid electric vehicle (HEV) may affect the distance from which the approaching vehicle can be detected by pedestrians who are blind.

Global sales of hybrid and battery electric vehicles are expected to more than triple to 7.3 percent in 2020 from 2.2 percent in 2010 [7], and more than 140 different commercially available hybrid and battery electric vehicle models were listed by Hybridcars.com in 2010. The potential impact of this increasing number of hybrid and battery electric vehicles on the mobility of pedestrians with visual impairments has been a topic of interest in popular media in recent years [8-10]. The main story line has been that quieter vehicles in the roadways pose a threat to blind pedestrians who often rely on hearing vehicles to navigate and travel safely. However, many articles have based their claims on anecdotal evidence

Abbreviations: ANOVA $=$ analysis of variance, CHHS $=$ College of Health and Human Services, HEV = hybrid electric vehicle, ICE = internal combustion engine, $\mathrm{O} \& \mathrm{M}=$ orientation and mobility, $\mathrm{SD}=$ standard deviation, VSP $=$ Vehicle Sound for Pedestrians, WMU = Western Michigan University.

*Address all correspondence to Dae Shik Kim, PhD; Western Michigan University, Department of Blindness and Low Vision Studies, 1903 W Michigan Ave, Kalamazoo, MI 49008-5218; 269-387-3447; fax: 269-387-3567.

Email: dae.kim@wmich.edu

http://dx.doi.org/10.1682/JRRD.2011.03.0041 
and speculation; few empirical studies have demonstrated whether, to what degree, and in what ways the presence of quieter vehicles could affect blind pedestrians' ability to travel in different environments.

Many key orientation tasks performed by blind travelers involve the use of traffic sounds [2,11-13]. For example, they use traffic sounds to align themselves correctly before crossing a street [14-15], as well as to gauge whether they are veering while crossing a street [11-12]. Traffic sounds are also used to identify an appropriate time to initiate street crossing $[1,12]$ and to determine whether the vehicles in the parallel street are turning into the pedestrian's travel path [1-2].

Regardless of which of these tasks is needed, a blind pedestrian must first detect the presence of an approaching vehicle to initiate an appropriate decision-making process [16]. Furthermore, the ability to detect the presence of an approaching vehicle at a sufficient distance is critical for the safety of a blind pedestrian when he or she needs to cross a street with no traffic signals (e.g., residential streets, roundabouts, channelized turn lanes) [2,16-18]. In addition, failure to detect the presence of a vehicle that is backing up, particularly when the pedestrian is traversing driveways, walking along a parking lot aisle, or traveling near construction sites, may result in collision with the vehicle (Personal communication, R. LaDuke, EdD, 2010 Dec 13; M. Weessies, MA, 2010 Dec 11) and consequent collision-induced injuries.

Vehicle type appears to affect a pedestrian's ability to detect the vehicle because different vehicles may have different acoustic characteristics, including sound emitted, frequency, and modulation [19-24]. Higher sound pressure level is linked to an increase in the perceptual experience of loudness and threshold of hearing [19,2123]. Sound frequencies establish the perceptual experience of pitch (described as "high" or "low") and also affect the threshold of hearing [21]. This is because the human ear is most sensitive to frequencies in the neighborhood of $2.5 \mathrm{kHz}$ and threshold intensity increases with the departure from this frequency [19,21-23].

The sound from moving vehicles primarily comes from mechanical noise and tire noise [24]. During initial acceleration, in which the first or second gear is engaged, engine noise is predominant, whereas the tire noise becomes the prevailing sound when the vehicle is moving at high speed [25]. Wiener et al. documented that an HEV emitted much lower auditory output than the comparable internal combustion engine (ICE) vehicle when accelerating slowly from a stationary position (reaching $10 \mathrm{~km} / \mathrm{h}$ in $5 \mathrm{~s}$ ) [6]. The A-weighted $2 \mathrm{kHz}$ octave band level was found to be $43 \mathrm{dBA}$ for the HEV and $63 \mathrm{dBA}$ for the comparable ICE vehicle. Robart and Rosenblum reported that when binaural recordings of approaching vehicles (constant speed of $8 \mathrm{~km} / \mathrm{h}$ ) were played through earphones, participants detected HEVs (2004 and 2006 Toyota Prius) 2 to $4 \mathrm{~s}$ later than the ICE vehicles (2004 Honda Accord, 2005 Ford Mustang) [26].

In a study conducted in the downtown area of a college town (Kalamazoo, Michigan), surges (starting up from a stationary position) of HEVs were missed at a higher percentage (7.4\%-45.7\%) than those of ICE vehicles (2.2\%) [27]. Furthermore, the National Highway Traffic Safety Administration, using the pedestrian crash data from 12 states, documented that the accident rate of HEVs was twice as high as that of the ICE vehicles in low-speed maneuver conditions, including slowing, stopping, backing up, and entering a parking space [28]. However, we found no published studies that examined how adding an artificially generated sound to an HEV (or a battery electric vehicle) affects its detectability.

Environmental characteristics also seem to affect an individual's ability to detect an approaching vehicle because signals (e.g., vehicle sound) are always detected against a background of activity (e.g., ambient noise) $[4,29]$. Human hearing threshold is affected not only by the sound intensity signal-to-noise ratio [3,16], but also by the difference in frequency characteristics between the target and background sounds [30-33]. Background noise can more effectively mask a target sound when it contains the frequencies at or near those of the target sound [32]. Provided that the frequencies of the target sound are near those of the masking sound, the masking effect increases linearly with the masker's intensity, while this relationship is more complex when their frequencies are far apart [34]. Interestingly, a target sound is more readily masked by background noise whose frequency composition is slightly lower than the target sound frequency compared with the background noise composed of frequencies slightly higher than the target sound frequency [32,34].

In their study examining blind individuals' abilities to detect approaching vehicles in a midblock, Wall Emerson and Sauerburger found the ambient sound level to be the strongest predictor of how early the vehicles were detected [35]. However, we have not found any published studies that investigated the interaction effects of the vehicle and environmental characteristics on vehicle detectability. 
One of the primary purposes of this study was to investigate how adding an artificially generated sound affected the detectability of an HEV. Another purpose of the study was to examine how different test sites affected vehicle detectability as they interacted with the effects of different vehicle sounds.

\section{METHODS}

\section{Study Design and Participant Demographics}

This study used a repeated-measures design with block randomization (vehicle order was randomized within each block of three vehicles) [36] in which the participants performed each of the orientation and mobility (O\&M)-related tasks (described in "Research Procedure" section) under one of the three vehicle conditions (described in "Apparatus" section). Fifteen legally blind adults who traveled independently at least in familiar areas were recruited for the study. Fourteen successfully completed all tasks outlined by the study protocol.

The participants (eight males, six females) ranged in age from 18 to 68 (Table 1). Their visual acuities ranged from no light perception to $20 / 200$. Seven of the participants were congenitally blind, while the other half lost their vision later in life. The etiologies of the participants' visual impairments included retinopathy of prematurity $(n=3)$, glaucoma $(n=2)$, retinal detachment $(n=2)$, and retinitis pigmentosa $(n=1)$, among others. Two of the participants had moderate hearing loss (45-70 dB) in higher frequencies (4-8 KHz) (Table 2).

\section{Apparatus}

Three different vehicles were used for each O\&M task: a midsize HEV sedan, the same make and model HEV sedan with the Vehicle Sound for Pedestrians (VSP) system, and the same make and model ICE sedan. The VSP system was developed with the aims of (1) emphasizing frequency content between 600 and $800 \mathrm{~Hz}$ to enhance detectability for older pedestrians with higher frequency hearing loss, (2) providing adequate frequency content between 2 and $5 \mathrm{KHz}$ to facilitate detectability for those with normal hearing, and (3) reducing frequency content at around $1 \mathrm{KHz}$ to minimize noise intrusion to the neighboring communities and to the passenger cabin. The forward VSP sound tested in this study bears a whoosh character and has two equally prominent peaks: $630 \mathrm{~Hz}$ and $2.5 \mathrm{KHz}$ (Figures 1-2).
Table 1.

Participant characteristics

\begin{tabular}{cccccl}
\hline Participant & Sex & Age & $\begin{array}{c}\text { Visual } \\
\text { Acuity }\end{array}$ & $\begin{array}{c}\text { Age at VI } \\
\text { Onset }\end{array}$ & \multicolumn{1}{c}{ Etiology } \\
\hline 1 & F & 43 & NLP & 33 & Uveitis \\
2 & F & 51 & NLP & Birth & Retinopathy of prematurity \\
3 & F & 49 & LP & Birth & Retinopathy of prematurity \\
4 & M & 18 & LP & Birth & Lieber’s amaurosis \\
5 & M & 61 & NLP & Birth & Retinopathy of prematurity \\
6 & M & 68 & LP & 8 & Retinitis pigmentosa \\
$7^{*}$ & F & 77 & LProj & 56 & Retinitis pigmentosa \\
8 & M & 29 & LP & Birth & Unknown \\
9 & M & 22 & LP & Birth & Unknown \\
10 & F & 25 & NLP & Birth & Glaucoma \\
11 & M & 52 & NLP & 6 & Glaucoma \\
12 & M & 42 & NLP & 31 & Diabetic retinopathy \\
13 & M & 21 & HM at $2 \mathrm{ft}$ & 10 & Chemical burn \\
14 & F & 59 & $20 / 400$ & 54 & Retinal detachment \\
15 & F & 23 & $20 / 200$ & 20 & Retinal detachment
\end{tabular}

${ }^{*}$ Excluded from analyses because participant did not follow experimental protocol. $\mathrm{F}=$ female, $\mathrm{HM}=$ hand movement, $\mathrm{LP}=$ light perception, $\mathrm{LProj}=$ light projection, $\mathrm{M}=$ male, $\mathrm{NLP}=$ no light perception, $\mathrm{VI}=$ visual impairment.

Table 2.

Participant hearing threshold (decibels).

\begin{tabular}{cccccccc}
\hline Participant & $\mathbf{1 2 5} \mathbf{~ H z}$ & $\mathbf{2 5 0} \mathbf{~ H z}$ & $\mathbf{5 0 0} \mathbf{~ H z}$ & $\mathbf{1 ~ K H z}$ & $\mathbf{2 ~ K H z}$ & $\mathbf{4 ~ K H z}$ & $\mathbf{8 ~ K H z}$ \\
\hline 1 & 20 & 20 & 20 & 20 & 20 & 30 & 30 \\
2 & 20 & 20 & 20 & 25 & 20 & 25 & 25 \\
3 & 20 & 20 & 20 & 20 & 30 & 20 & 35 \\
4 & 20 & 20 & 20 & 20 & 20 & 20 & 20 \\
5 & 20 & 20 & 20 & 20 & 20 & 30 & 30 \\
6 & 20 & 20 & 20 & 20 & 30 & 45 & 70 \\
$7^{*}$ & 30 & 30 & 30 & 30 & 40 & 65 & 80 \\
8 & 20 & 20 & 20 & 20 & 20 & 20 & 20 \\
9 & 20 & 20 & 30 & 20 & 20 & 20 & 30 \\
10 & 30 & 30 & 35 & 40 & 45 & 45 & 55 \\
11 & 20 & 20 & 20 & 20 & 20 & 20 & 25 \\
12 & 20 & 20 & 20 & 20 & 20 & 20 & 20 \\
13 & 20 & 20 & 20 & 20 & 20 & 20 & 20 \\
14 & 20 & 20 & 20 & 20 & 20 & 20 & 20 \\
15 & 20 & 20 & 20 & 20 & 20 & 20 & 20
\end{tabular}

*Excluded from analyses because participant did not follow experimental protocol.

The backward VSP sound has a primary peak at $2 \mathrm{KHz}$ and a secondary peak at $630 \mathrm{~Hz}$ with conspicuous amplitude modulation (Figures 3-4), which resembles the backward warning beep used by large commercial vehicles. Among more than 100 different candidate sounds, the final VSP sounds were selected primarily based on testing in a hearing research laboratory, but also on subjective appeal and compatibility with the VSP system speaker. Both the forward and backward VSP sounds emanate from the same speaker mounted behind the front fascia in the engine compartment. 


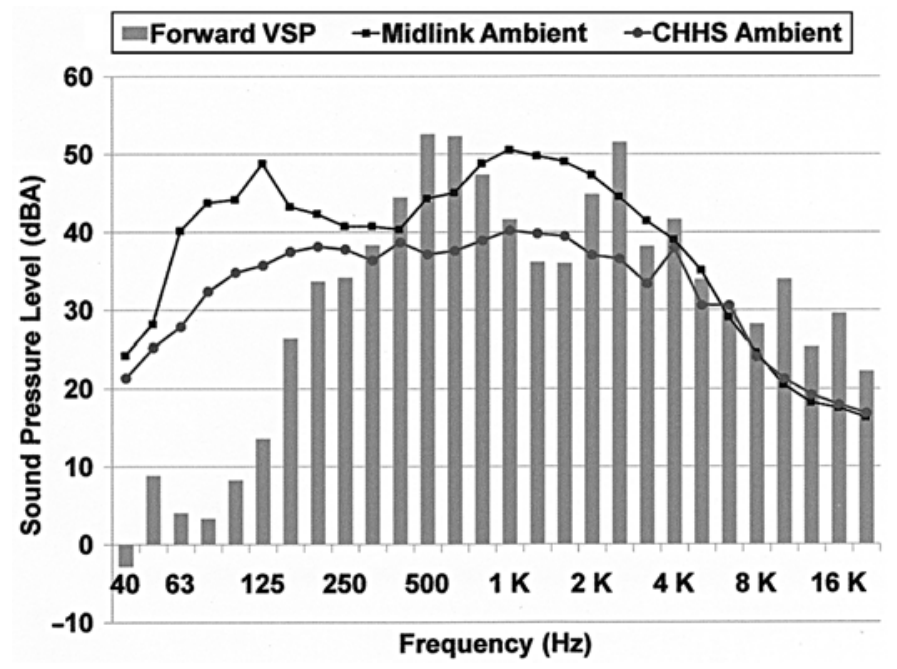

Figure 1.

One-third octave frequency spectrum of forward Vehicle Sound for Pedestrians (VSP) sound at idle. CHHS = College of Health and Human Services (parking lot), Midlink = Midlink Business Park (roadway).

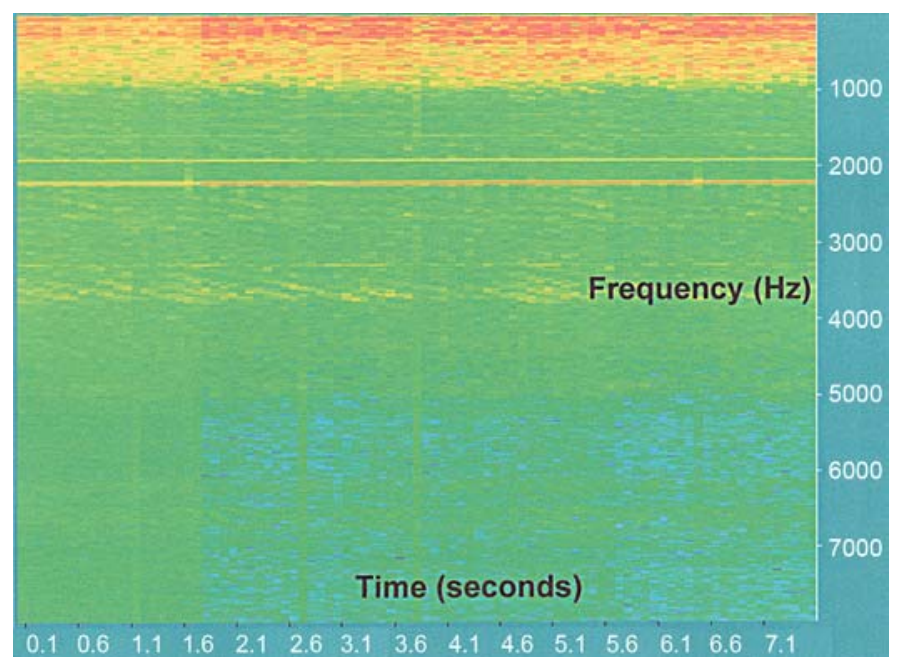

\section{Figure 2.}

Spectrogram of forward Vehicle Sound for Pedestrians sound at idle.

Three GPS (Global Positioning System) data-logging system units (VBOX Micro RLVBNIC01C, Racelogic; Buckingham, England) were used to record the position and velocity of each vehicle every $100 \mathrm{~ms}$ during each trial. A total of seven radio controller handsets $(2.4 \mathrm{GHz}, 2$ channels, Traxxas; Plano, Texas) were used: one for each of the five participants, one for the experimenter who time-

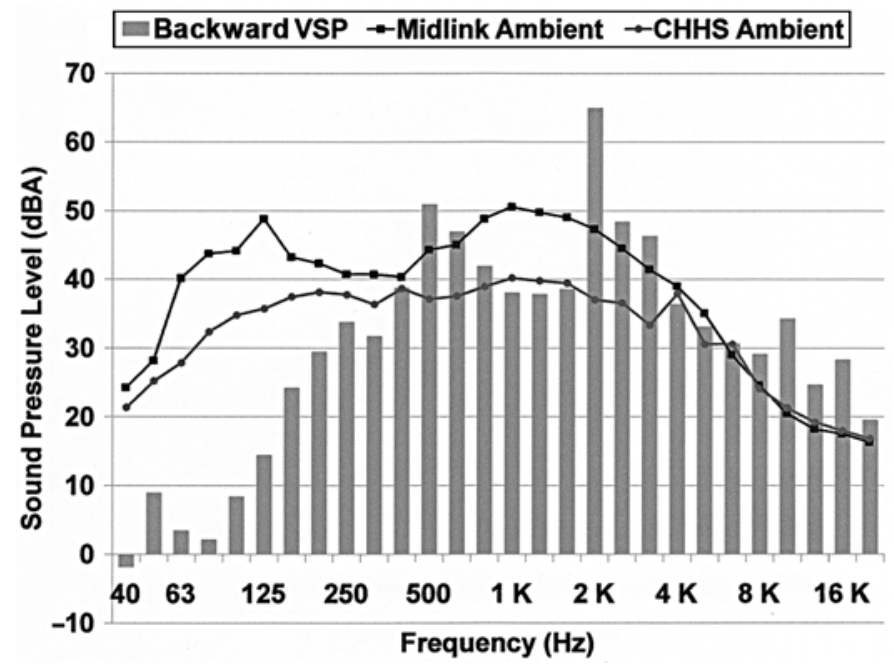

Figure 3.

One-third octave frequency spectrum of backward Vehicle Sound for Pedestrians (VSP) sound at idle. CHHS = College of Health and Human Services (parking lot), Midlink = Midlink Business Park (roadway).

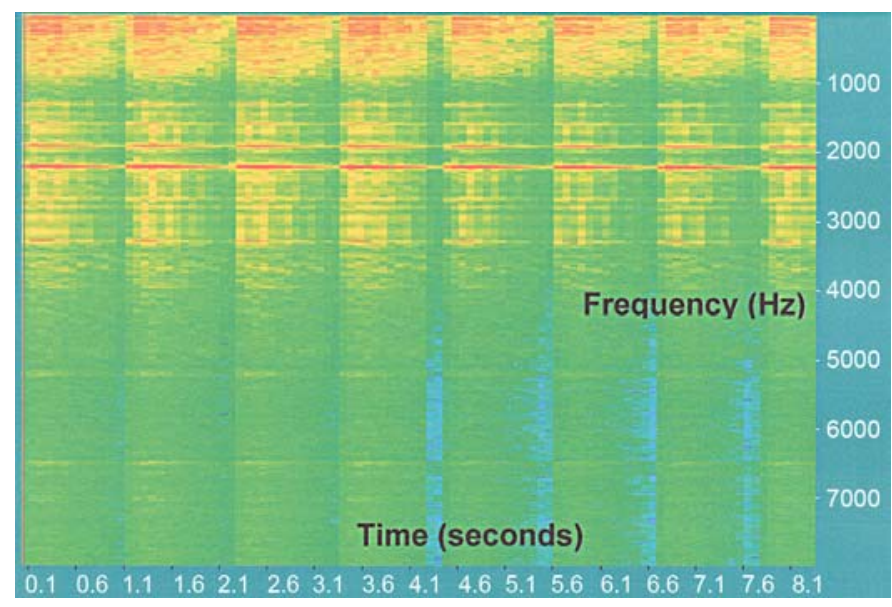

\section{Figure 4.}

Spectrogram of backward Vehicle Sound for Pedestrians sound at idle.

stamped each vehicle pass at the sound level meter, and one for the other experimenter who time-stamped the beginning of each trial. The sound level meter (CEL-490, class 1 SLM, Casella; Amherst, New Hampshire) was positioned next to the participant nearest to the approaching vehicle. A Dell Latitude E6500 laptop (Dell Inc; Round Rock, Texas) along with a National Instruments chassis (NI cDAQ-9172, National Instruments; Austin, Texas) containing three NI-9234 four-channel data acquisition 
cards recorded the sound level meter output as well as each trigger pull and release of each radio controller during all trials. A digital camcorder (VIXIA HF20, Canon; Tokyo, Japan) was used to record all trials.

Each participant's hearing was tested using an audiometer (Beltone Special Instruments 120 Audiometer; Glenview, Illinois) in a hearing test room located in Western Michigan University's (WMU's) College of Health and Human Services (CHHS) building. Thresholds were determined at 120, 250, 500, 1000, 2000, 4000, and $8000 \mathrm{~Hz}$.

\section{Research Procedure}

Detection data were gathered for three vehicle conditions: (1) a midsize HEV sedan operated in electric vehicle mode, (2) the same make and model HEV sedan operated in electric vehicle mode with the VSP system on, and (3) the same make and model ICE sedan in ICE mode (no electric vehicle mode available). The sound level of the first condition was $48.6 \mathrm{dBA}$ when measured at $2 \mathrm{~m}$ in front of the vehicle grill while idling in an anechoic chamber. The sound levels of the second (forward sound) and third conditions were measured at 58.3 and $54.6 \mathrm{dBA}$, respectively, in the same setting. The backward VSP sound was measured at $64.6 \mathrm{dBA}$ in the same anechoic chamber condition. The one-third octave frequency spectrum of each of the four conditions (forward VSP sound, backward VSP sound, HEV, and ICE) recorded in an anechoic chamber is shown in Figures 1, 3, 5, and 6.

The forward pass-by sound levels (constant speed of $15 \mathrm{~km} / \mathrm{h}$ ) measured at a vehicle test track (microphone was located $1.2 \mathrm{~m}$ from the ground and $2 \mathrm{~m}$ from the center of the vehicle as each vehicle passed) were 59.9, 63.3, and $59.7 \mathrm{dBA}$ for the HEV, VSP, and ICE conditions, respectively. In the same setting, the backward pass-by sound levels at a constant speed of $10 \mathrm{~km} / \mathrm{h}$ were measured at 54.1, 66.3, and 58.1 dBA for the HEV, VSP, and ICE conditions, respectively. These three vehicles had identical tires.

Parking lots and roadways are among the most frequently identified locations where quiet cars may pose threats to blind pedestrians' safety [37-38]. WMU's CHHS parking lot was chosen as one of the testing sites in light of its low ambient sound level and its elongated dimension that allowed the vehicles to stage beyond the earshot of the participants (Figures 7-8). Midlink Drive, a roadway next to the Midlink Business Park in Portage, Michigan, was selected as the other testing site given its moderately high level of ambient sound that was dominated by traffic noise (Figures 9-10).

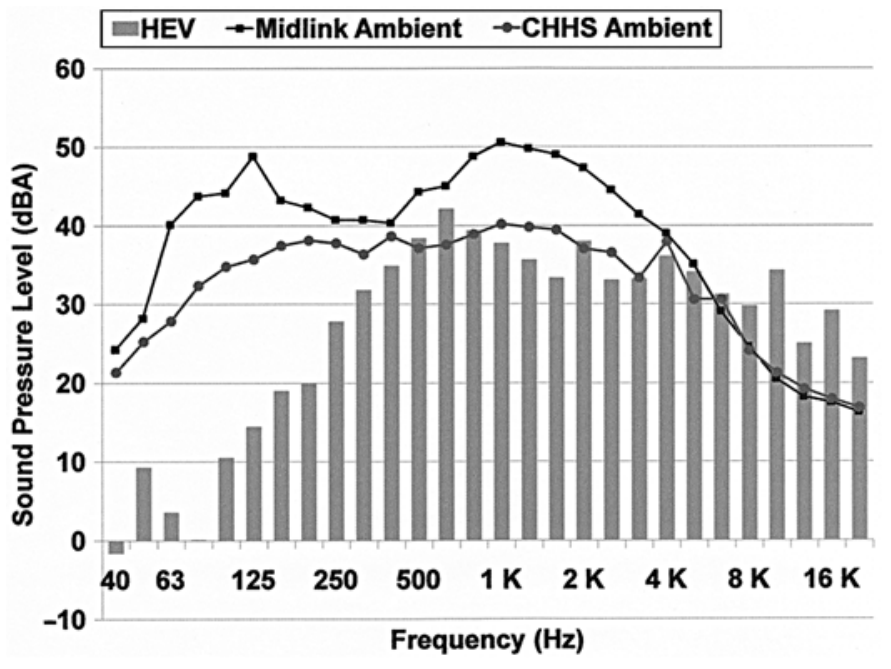

Figure 5.

One-third octave frequency spectrum of hybrid electric vehicle (HEV) at idle. $\mathrm{CHHS}=$ College of Health and Human Services (parking lot), Midlink = Midlink Business Park (roadway).

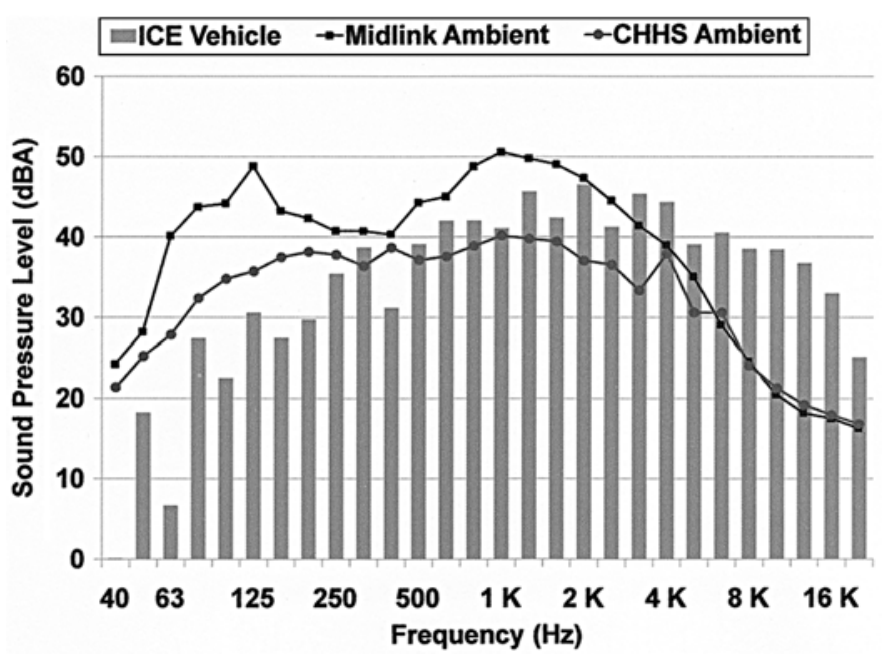

Figure 6.

One-third octave frequency of internal combustion engine (ICE) vehicle at idle. $\mathrm{CHHS}=$ College of Health and Human Services (parking lot), Midlink = Midlink Business Park (roadway).

Average ambient sound level (measured at three different times on each of the three testing days) at the CHHS parking lot was $48.7 \mathrm{dBA}( \pm 2.1 \mathrm{dBA})$, while that at the Midlink Drive roadway was $55.1 \mathrm{dBA}( \pm 4.0 \mathrm{dBA})$. Ambient sound at the Midlink Drive test site was predominated by the traffic sounds from the nearby expressway (Interstate 94) and a busy 4-lane street (Sprinkle Road). 


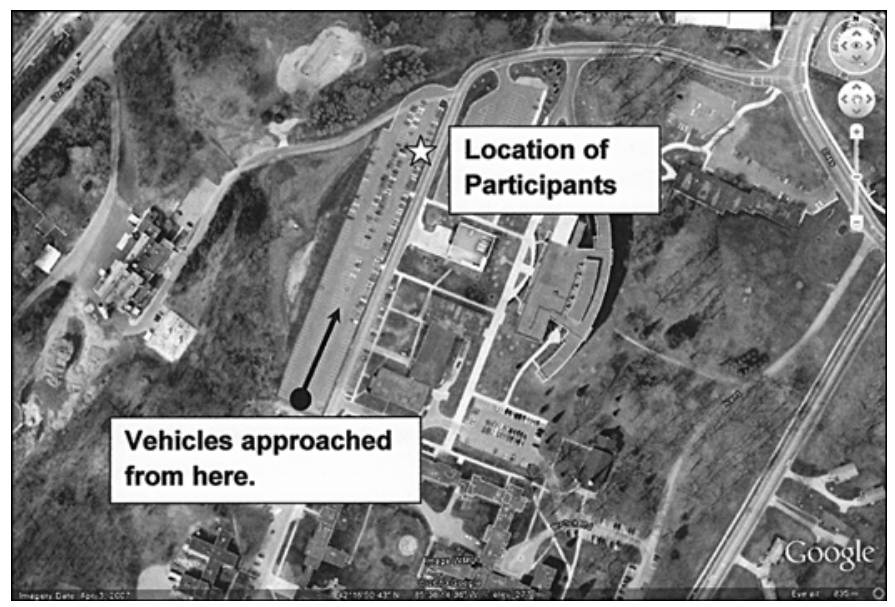

Figure 7.

Aerial view of College of Health and Human Services parking lot.

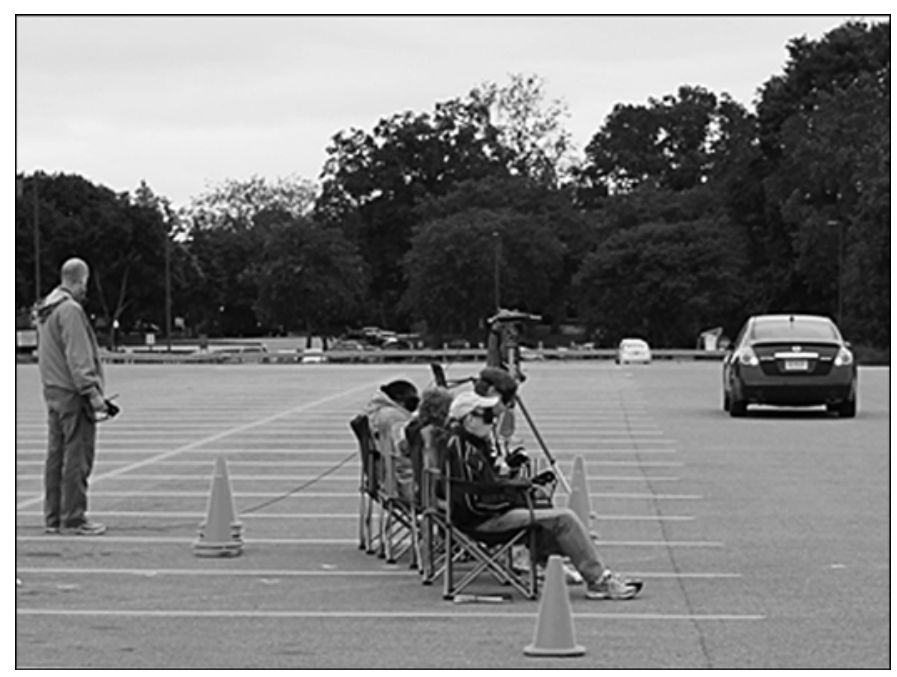

Figure 8.

Backward approach at College of Health and Human Services parking lot.

In contrast, although mostly empty during our data collection (tests were conducted only on weekends), the ambient sound at the CHHS parking lot was a mixture of traffic sounds, bird chirping, sounds from intermittent student activities (e.g., marching band practice from a distance, conversations from students walking by), and sporadic airplane sounds from a distance. A representative one-third octave band frequency spectrum of each site is shown in Figure 1 (overlaid on top of vehicle frequency plots with gray and black lines).

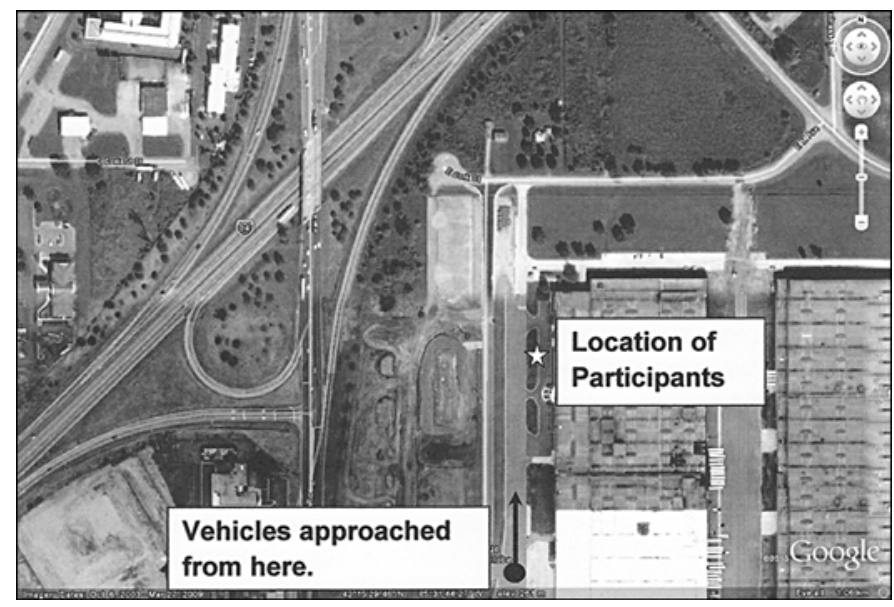

\section{Figure 9.}

Aerial view of Midlink Business Park roadway.

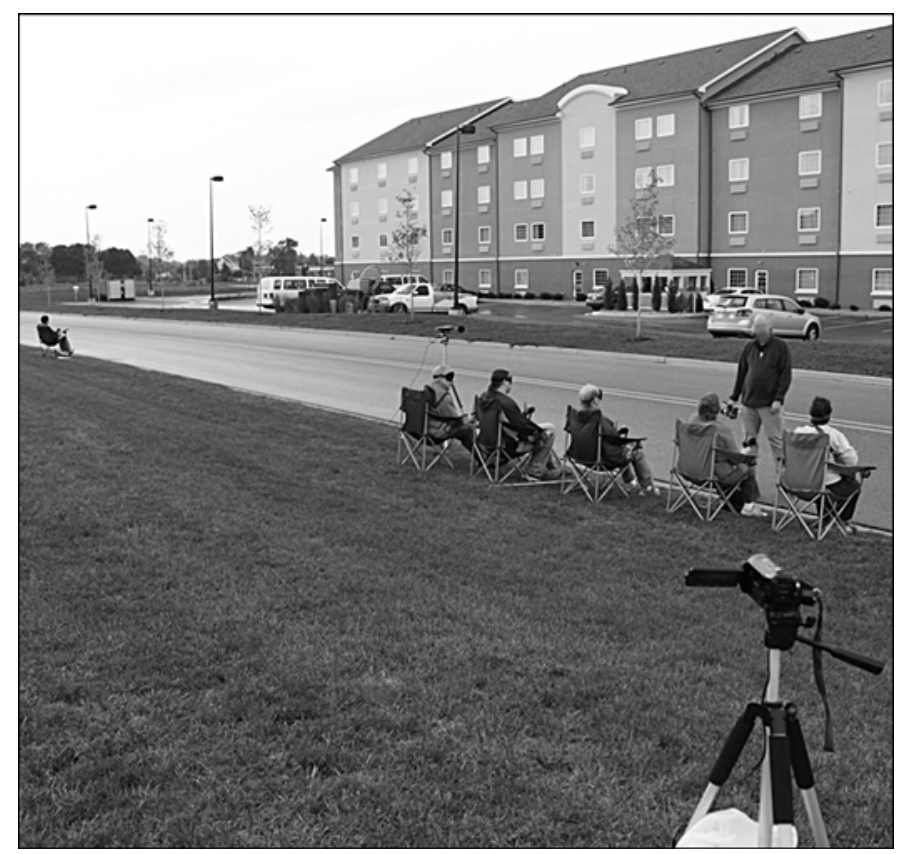

Figure 10.

Approach lane at Midlink Business Park.

The participants learned about the experimental procedure through verbal briefing and one practice trial. Each group of five subjects was tested over the course of 2 days (15 participants in total). For all tasks, participants held radio controller handsets that communicated wirelessly with the data acquisition system. Participants pulled the trigger on the controller to register an event. The sound level meter took continuous readings 
throughout the trials and recorded background sound levels as well as the sound levels of passing vehicles. Trials were stopped momentarily during extraneous noise events (e.g., low-flying airplanes, nearby leaf blowers).

All participants wore sleep shades during all trials. They were seated on the right side of the vehicle path approximately $2 \mathrm{~m}$ from the side of a passing vehicle (Figure 5). Seating was staggered slightly to prevent one participant from being a sound shadow for another. Participants were instructed to pull the radio controller trigger when they were sure they heard a vehicle approaching. Radio controller triggers were virtually silent and the participants were told to sit as still as possible during the trials in order to prevent adjacent participants from receiving any cues on when to pull the trigger. Three V-Boxes (one on each vehicle) were used to record the vehicle position and velocity at the time of vehicle detection (trigger pull) by each participant. All data from the sound level meter, radio controller handsets, and V-Boxes were fed into a central laptop computer.

Groups of five participants were tested simultaneously. Vehicles were staged beyond the detectable distance so that the participants could not hear the vehicles moving into their starting positions. The vehicles approached the participants at a constant speed of $15 \mathrm{~km} / \mathrm{h}$ for the forward and $10 \mathrm{~km} / \mathrm{h}$ for the backward detection tasks. The backward detection task was included in the study because the VSP system engaged different sounds for the forward and backward approaches (Figures 1-4). The order of approaching vehicles was randomly determined to prevent participants from anticipating a certain vehicle in a given trial. Five trials were completed for each of the six vehicle approach conditions, which resulted in 30 trials (3 vehicles $\times 2$ approach conditions [forward, backward] $\times 5$ trial repetitions) for each participant at each site. Identical procedures were used at both the CHHS parking lot and the Midlink Drive roadway.

\section{Variables}

Vehicle detection distance and crossing margin were used to measure participants' detection performance. Vehicle detection distance was defined as the distance from the sound level meter (positioned next to the participants) to the approaching vehicle at the moment of trigger pull by the participant. Crossing margin was calculated by subtracting the time it takes for a pedestrian to cross a 2-lane street (6.9 s) from the time it would take for the vehicle to reach the sound level meter. A lane width of $12 \mathrm{ft}$ and a walking speed of $3.5 \mathrm{ft} / \mathrm{s}$ (per Manual on Uniform Traffic Control Devices) were used for calculating crossing margins.
Independent variables of the study included vehicle type (within-group variable with three categories: HEV, HEV with VSP, and ICE vehicle) and the test site (withingroup variable with two categories: CHHS parking lot and Midlink Drive roadway).

\section{Analyses}

Upon completing a series of preliminary descriptive statistical procedures, we conducted a two-way repeatedmeasures analysis of variance (ANOVA) to examine the main effects and interaction effects of vehicle type and test site. In case of the violation of the sphericity assumption, adjustments were made to the ANOVA results by using Greenhouse-Geisser degree of freedom correction. Repeated-measures $t$-tests were used for pairwise post hoc comparisons. We used a significance level of 0.05 for all statistical tests (two-tailed); Bonferroni correction was used for all pairwise post hoc tests. The statistical power was at least 0.82 for all ANOVA and post hoc $t$-tests when a large effect size ( $f=0.4, d=0.8$ ) was assumed [39-40]. G*Power version 3.0.10 (http://www.psycho.uniduesseldorf.de/abteilungen/aap/gpower3/) was used for statistical power analyses, while SPSS version 16.0 (SPSS Inc; Chicago, Illinois) was used for all other analyses.

\section{RESULTS}

\section{Forward Moving Vehicle Detection}

Data from 14 of the 15 participants were usable for analyses. No statistically significant interaction was observed between the test site and vehicle condition, $F(1.31,16.98)=0.272, p=0.67$ (Figure 11); therefore, the main effects of these two variables were examined [41]. A statistically significant difference existed in detection distance between the vehicles, $F(1.42,18.46)=$ 16.480, $p<0.001$ (Table 3). Similarly, a statistically significant difference existed in crossing margin between the vehicles, $F(1.43,18.56)=17.784, p<0.001$.

Post hoc analyses revealed that the detection distance for the HEV (mean \pm standard deviation [SD] $=27.5 \pm$ $11.5 \mathrm{~m}$ ) was statistically significantly shorter than that for the VSP vehicle (mean $\pm \mathrm{SD}=38.3 \pm 14.8 \mathrm{~m}$ ), $t=-4.823$, $p<0.001$, and that for the ICE vehicle (mean $\pm \mathrm{SD}=34.5 \pm$ $14.3 \mathrm{~m}), t=-6.058, p<0.001$. However, no statistically significant difference existed between the VSP and ICE vehicles, $t=1.787, p=0.10$. Similarly, the crossing margin for the HEV (mean \pm SD $=-0.4 \pm 2.7$ s) was statistically significantly shorter than that for the VSP vehicle 
(mean $\pm \mathrm{SD}=2.1 \pm 3.5 \mathrm{~s}$ ), $t=-4.656, p<0.001$, and that for the ICE vehicle (mean $\pm \mathrm{SD}=1.7 \pm 3.4 \mathrm{~s}$ ), $t=-7.467, p$ $<0.001$. However, no statistically significant difference existed between the VSP and ICE vehicles, $t=0.872$, $p=0.40$.

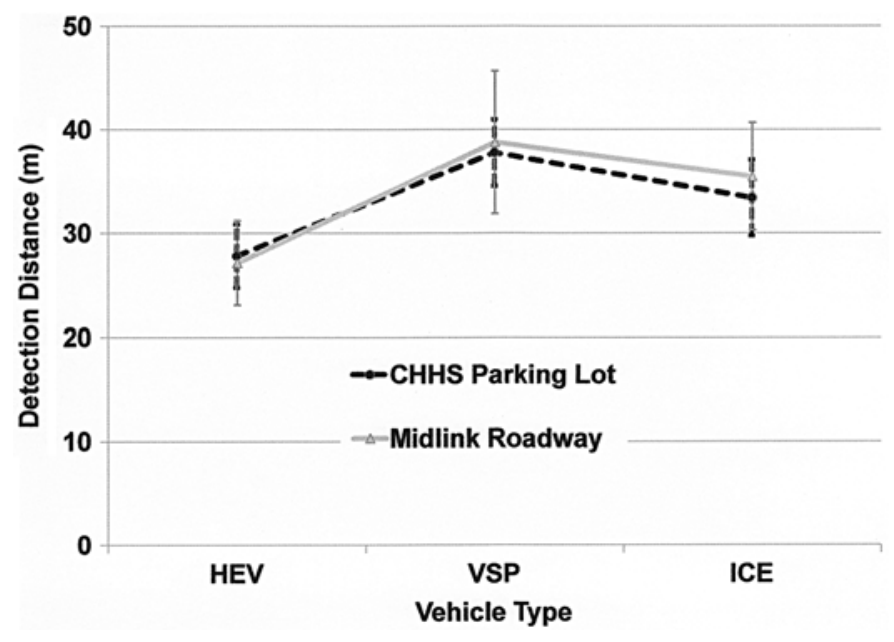

Figure 11.

Interaction between vehicle type and test site (forward detection). Error bars indicate standard errors. CHHS = College of Health and Human Services, HEV = hybrid electric vehicle, ICE = internal combustion engine, $\mathrm{VSP}=$ Vehicle Sound for Pedestrians.

Table 3.

Forward and backward detection performance by vehicle and test site $(N=14)$.

\begin{tabular}{|c|c|c|c|c|}
\hline \multirow{2}{*}{ Variable } & \multicolumn{2}{|c|}{ Detection Distance (m) } & \multicolumn{2}{|c|}{ Crossing Margin (s) } \\
\hline & Mean \pm SD & $p$-Value & Mean \pm SD & $p$-Value \\
\hline \multicolumn{5}{|l|}{ Forward Detection } \\
\hline Vehicle & & $<0.001$ & & $<0.001$ \\
\hline HEV & $27.5 \mathrm{a} \pm 11.5$ & & $-0.4_{a} \pm 2.7$ & \\
\hline VSP & $38.3_{\mathrm{b}} \pm 14.8$ & & $2.1_{b} \pm 3.5$ & \\
\hline ICE & $34.5 \mathrm{~b} \pm 14.3$ & & $1.7_{b} \pm 3.4$ & \\
\hline Testing Site & & 0.88 & & 0.78 \\
\hline Parking Lot & $33.0 \pm 11.7$ & & $1.0 \pm 2.7$ & \\
\hline Roadway & $33.8 \pm 19.4$ & & $1.3 \pm 4.7$ & \\
\hline \multicolumn{5}{|c|}{ Backward Detection } \\
\hline Vehicle & & $<0.001$ & & $<0.001$ \\
\hline $\mathrm{HEV}$ & $25.1_{\mathrm{a}} \pm 9.5$ & & $2.5_{a} \pm 3.7$ & \\
\hline VSP & $51.8 \mathrm{~b} \pm 18.0$ & & $9.5_{b} \pm 6.0$ & \\
\hline ICE & $30.5 \mathrm{c} \pm 11.2$ & & $3.2_{a} \pm 3.7$ & \\
\hline Testing Site & & 0.20 & & 0.15 \\
\hline Parking Lot & $32.9 \pm 8.6$ & & $3.9 \pm 2.6$ & \\
\hline Roadway & $38.8 \pm 17.2$ & & $6.3 \pm 6.3$ & \\
\hline \multicolumn{5}{|c|}{$\begin{array}{l}\text { Note: Differing subscripts within each measure indicate significant differences } \\
\text { between means at } \alpha=0.17 \text { (Bonferroni correction). Like subscripts within } \\
\text { each measure indicate nonsignificant differences between mean values. } \\
\text { HEV = hybrid electric vehicle, ICE = internal combustion engine, SD = stan- } \\
\text { dard deviation, VSP = Vehicle Sound for Pedestrians. }\end{array}$} \\
\hline
\end{tabular}

Detection distance at the CHHS parking lot (mean \pm $\mathrm{SD}=33.0 \pm 11.7 \mathrm{~m}$ ) was not statistically significantly different from that at the Midlink Drive roadway (mean \pm $\mathrm{SD}=33.8 \pm 19.4 \mathrm{~m}$ ), $F(1,13)=0.025, p=0.88$ (Table 3). Similarly, no statistically significant difference existed in crossing margin between the two sites (CHHS $=1.0 \pm 2.7 \mathrm{~s}$, Midlink $=1.3 \pm 4.7$ s), $F(1,13)=0.082, p=0.78$.

\section{Backward Moving Vehicle Detection}

No statistically significant interaction was observed between the test site and vehicle condition, $F(1.12,14.50)=$ 3.810, $p=0.67$ (Figure 12); therefore, the main effects of these two variables were examined [41]. A statistically significant difference existed in detection distance between the vehicles, $F(1.11,14.44)=28.751, p<0.001$ (Table 3). Similarly, a statistically significant difference existed in crossing margin between the vehicles, $F(1.10,14.26)=$ 22.120, $p<0.001$.

Post hoc analyses showed that the detection distance for the VSP vehicle (mean $\pm \mathrm{SD}=51.8 \pm 18.1 \mathrm{~m}$ ) was statistically significantly longer than that for the ICE vehicle (mean $\pm \mathrm{SD}=30.5 \pm 11.2 \mathrm{~m}$ ), $t=5.985, p<$ 0.001 , which in turn was statistically significantly longer than that for the HEV (mean $\pm \mathrm{SD}=25.1 \pm 9.5 \mathrm{~m}$ ), $t=$ 4.416, $p=0.001$. Regarding crossing margin, the VSP vehicle's crossing margin (mean $\pm \mathrm{SD}=9.5 \pm 6.0 \mathrm{~s}$ ) was statistically significantly longer than that for the ICE vehicle (mean $\pm \mathrm{SD}=3.2 \pm 3.7 \mathrm{~s}$ ), $t=4.534, p=0.001$,

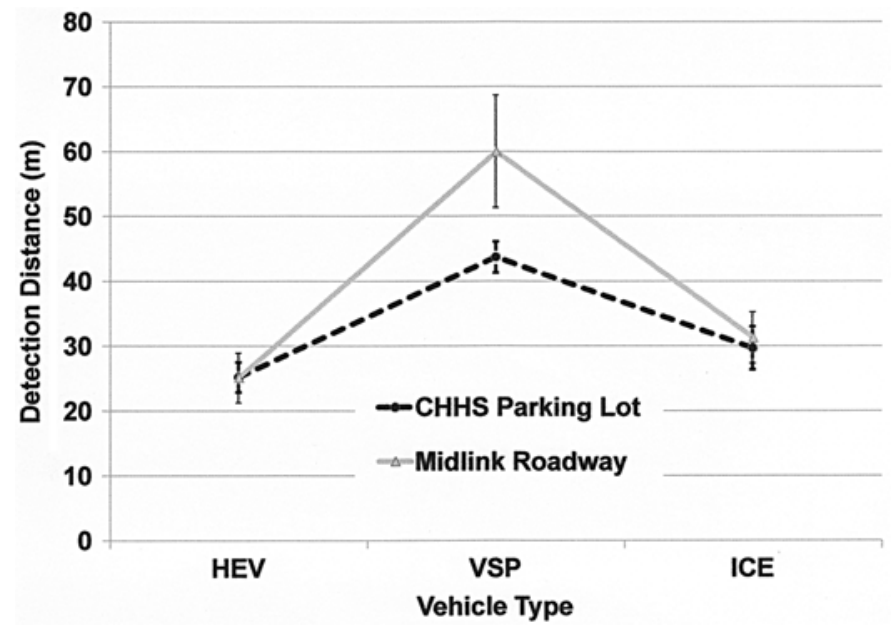

Figure 12.

Interaction between vehicle type and test site (backward detection). Error bars indicate standard errors. CHHS = College of Health and Human Services, HEV = hybrid electric vehicle, ICE = internal combustion engine, VSP $=$ Vehicle Sound for Pedestrians. 
and that for the HEV (mean $\pm \mathrm{SD}=2.5 \pm \mathrm{s} 3.7 \mathrm{~s}$ ), $t=$ 4.973, $p<0.001$. However, no statistically significant difference existed between the HEV and ICE vehicle, $t=$ 2.110, $p=0.05$.

As shown in Table 3, the detection distance at the CHHS parking lot (mean $\pm \mathrm{SD}=32.9 \pm 8.6 \mathrm{~m}$ ) was not statistically significantly different from that at the Midlink Drive roadway (mean $\pm \mathrm{SD}=38.8 \pm 17.2 \mathrm{~m}$ ), $F(1,13)=1.785, p=0.20$. Similarly, no statistically significant difference existed in crossing margin between the two sites (CHHS $=3.9 \pm 2.6 \mathrm{~s}$, Midlink $=6.3 \pm 6.3 \mathrm{~s}$ ), $F(1,13)=2.289, p=0.15$. A post hoc power analysis indicated that this sample size $(N=14)$, with two-tailed tests and $\alpha=0.05$, yields statistical power of 0.41 for effect size of this magnitude $(f=0.25)$.

\section{DISCUSSION}

The VSP vehicle could be detected at a significantly farther distance than the HEV in both the forward approach and backward approach conditions. The VSP vehicle was similar to the ICE vehicle in forward detection distance but was detected at a significantly farther distance than the ICE vehicle in the backward approach condition. No significant interaction was found between the test site and the type of vehicle.

\section{Effect of Vehicle Sound}

Significantly longer forward detection distance of the VSP and ICE vehicles compared with that of the HEV is consistent with the literature on how signal-to-noise ratio affects detectability of a target sound against the background noise [3-4,29]; as indicated in the "Methods" section, the overall sound level (at idle) of the VSP and ICE vehicles was substantially higher than that of the HEV. The fact that the VSP vehicle was detected at a significantly farther distance than the ICE vehicle as well as the HEV in backward detection is also consistent with the literature on signal detection, because the sound level of the backward VSP sound (64.6 dBA) was much higher than that of the ICE vehicle (54.6 dBA) and the HEV (48.6 dBA).

While the overall sound level of the VSP (forward) vehicle was slightly higher than that of the ICE vehicle, detectability of these two vehicles was similar. We suspected that the participants' unfamiliarity with the VSP sound might have contributed to this result. However, neither practice effect (calculated from comparison of the responses of five repeated trials for a given condition), $F(4,36)=1.046, p=0.40$, nor the interaction between the vehicle type and practice, $F(2.361,21.25)=0.303$, $p=0.78$, turned out to be significant. A single practice trial for each vehicle appeared to have sufficiently familiarized the participants with the sounds, including the VSP sounds. Anecdotal evidence suggests that as a result of context effect, many synthesized sounds that do not closely resemble ICE sounds can be readily perceived as vehicle sounds when emitted by a moving vehicle in a roadway [19].

The differences in acoustic characteristics other than the overall sound level between the vehicles, including frequency spectral shape [30-32] and amplitude modulation [20], may have affected the detection performance outcome. There appears to be a greater difference in spectral shape between the VSP vehicle sound and the test site ambient noise than between the ICE vehicle sound and the test site ambient noise (Figures $\mathbf{1}$ and $\mathbf{6}$ ). Given that, it appears unlikely that the frequency spectral shape of the ICE vehicle worked to its advantage in detection performance. We were not able to identify clear amplitude modulation patterns in any of the ambient and vehicle sounds except for the backward VSP sound, which had a noticeable amplitude modulation.

\section{Effect of Background Sound}

Somewhat surprisingly, no significant difference in detection performance was found between the two test sites, which had a moderate difference in overall sound level (CHHS's 48.7 dBA vs Midlink Drive's $55.1 \mathrm{dBA}$ ). This result can be explained neither by the sound intensity signal-to-noise ratio difference between the two test sites nor by practice effects; all participants were tested at the Midlink Drive roadway first. One possible explanation may be that, compared with the CHHS parking lot, the frequency spectral shape of the Midlink Drive roadway's ambient sound was more distinct from those of the tested vehicle sounds. Frequency peaks of the HEV and ICE vehicle were around $630 \mathrm{~Hz}$ and $2 \mathrm{KHz}$, respectively (Figures 5-6). The forward VSP sound had two equally prominent peaks at $630 \mathrm{~Hz}$ and $2.5 \mathrm{KHz}$, while the backward VSP sound had a primary peak at $2 \mathrm{KHz}$ and the secondary peak at $630 \mathrm{~Hz}$ (Figures 1 and 3). The ambient sound at the Midlink Drive roadway had a noticeably lower sound intensity in the frequency bands near $400 \mathrm{~Hz}$ compared with that of the CHHS parking lot. Given the 
fact that a masking sound is more effective against target sounds of slightly higher frequency than against those of slightly lower frequency [32,34], a dip in the frequency spectrum in the neighborhood of $400 \mathrm{~Hz}$ at the Midlink Drive roadway may have allowed the vehicle sounds to be heard more easily by the participants.

Another possible explanation for similar detection performance between the CHHS parking lot and the Midlink Drive roadway may be found in the fact that the ambient sound at the CHHS parking lot was less predictable than that at the Midlink Drive roadway. In other words, the ambient sound at the Midlink Drive roadway was predominated by the traffic sounds from the nearby expressway and busy 4-lane street, whereas the ambient sound at the CHHS parking lot contained several distinctive sounds with different acoustic characteristics. Uncertainty in masking sound appears to deteriorate the detectability of the target sound [42-44]. Therefore, predictability in the type of ambient sound at the Midlink Drive roadway may have helped the participants detect the vehicles more effectively.

\section{Strengths and Limitations}

Some of the previous studies that examined the detectability of HEVs compared HEVs with similar-size ICE vehicles (e.g., Prius with Corolla). Although such comparison was not unreasonable, factors other than the difference in vehicle size might have confounded the results in those studies. In contrast, the vehicles compared in this study were of the same model. In particular, the HEV and the VSP vehicle were identical except for the fact that the VSP vehicle was equipped with the VSP system while the HEV was not. In addition, low-speed maneuver conditions as well as our thorough driver training allowed us to operate the vehicles precisely as intended. For example, the ICE engines of the HEV and the VSP vehicle were never engaged during any of our trials, which allowed us to examine the effect of the VSP system on detectability after controlling for the type of engaged power train at the time of detection.

Exclusion of "observer's criterion" [3] in the analyses prevented us from measuring each participant's performance in relation to his or her decision criterion. That is, the performance of the participants who had more false-positive trials (i.e., pulling the trigger when no vehicle was approaching) could have been inflated in comparison with those who had fewer such trials. In addition, although the radio controller triggers were virtually silent and the participants were instructed to avoid conspicuous hand and arm movements that may cue adjacent participants of their response, a participant's response might still have inadvertently influenced the response of adjacent participant(s) in very quiet ambient conditions. Furthermore, despite the vehicle order randomization within each block that consisted of three vehicles, the participants could deduce what the third vehicle would be in a given block by keeping track of the past vehicles. However, relatively similar false-positive rates for the three vehicles (HEV: 13.0\%, VSP: 11.6\%, ICE: $10.3 \%$ ) indicate the absence of noticeable response bias in favor of one vehicle over another.

Inclusion of only one artificially generated soundfor each of the forward and backward approaches_-did not allow us to identify which acoustic characteristics of the sounds significantly contributed to the difference in detection performance. In addition, this study omitted some of the key orientation tasks involved in blind pedestrians' everyday travel, such as vehicle surge detection, vehicle path discrimination, and alignment with the traffic in the parallel street.

\section{Implications and Recommendations}

Detecting approaching vehicles at a sufficient distance is critical for the safety of blind pedestrians. Given the significantly farther detection distance of the vehicle with an added artificially generated sound, automobile manufacturers may consider equipping hybrid and electric vehicles with a system that emits a sound to alert pedestrians in low-speed maneuver conditions. Particularly noteworthy was the improvement in crossing margin that resulted from adding the forward VSP sound (from -0.4 to $2.1 \mathrm{~s}$ ). That is, in the absence of a driver's evasive actions, a pedestrian would still be in the crosswalk when the HEV reached the crosswalk, but adding a VSP sound would provide the pedestrian a safety margin of $2.1 \mathrm{~s}$.

Although adding a backward VSP sound noticeably improved the crossing margin as well (from 2.5 to $9.5 \mathrm{~s}$ ), because the crossing margin for the HEV was positive even in the absence of added sound, equipping an HEV with a backward VSP sound may not have as salient practical merits as adding a forward VSP sound, at least in the conditions tested in this study. However, the use of a distinctive backward sound may have merit in that it can alert blind pedestrians to the possibility of the driver's limited ability to view the area behind the backing-up vehicle. 
That being said, we do not claim that adding an artificially generated sound will eliminate all the potential threats posed to blind travelers by quiet vehicles. Nor do we claim that adding an artificially generated sound is the best way to address the safety issues related to quiet vehicles. Instead, a thorough set of O\&M tasks needs to be tested with different types of artificially generated sounds as well as non-acoustic countermeasures to appropriately examine and provide solutions to the problems arising from the expanding fleet of quiet vehicles in the streets.

Future studies may include manipulating the acoustic characteristics of artificial sounds in a laboratory, with subsequent field studies for the selected sounds. Investigation of how vehicles with added sounds perform in other O\&M tasks, including surge detection and path discrimination, may also allow a fuller understanding of how these sounds may affect the safety of blind travelers. In addition, systematic inclusion of individuals with hearing impairments may allow us to examine how added artificial sounds affect individuals with hearing impairments differently than individuals without hearing impairments. Finally, investigation of non-acoustic countermeasures to the potential threats posed by quiet vehicles, including the technologies that allow vehicle-to-pedestrian communication and vehicleto-infrastructure communication may also be warranted.

\section{CONCLUSIONS}

An HEV with an added artificially generated sound was detected at a significantly farther distance than an HEV without the added sound. Given that detecting an approaching vehicle at a sufficient distance is critical for the safety of blind pedestrians, equipping hybrid and electric vehicles with a sound system that emits an alerting sound in certain low-speed maneuver conditions may contribute to the safety of blind pedestrians.

\section{ACKNOWLEDGMENTS}

\section{Author Contributions}

Study concept and design: D. S. Kim, R. Wall Emerson, K. Naghshineh. Acquisition of data: D. S. Kim, R. Wall Emerson, K. Naghshineh, J. Pliskow, K. Myers.

Analysis and interpretation of data: D. S. Kim, R. Wall Emerson, J. Pliskow, K. Myers.

Drafting of manuscript: D. S. Kim.

Critical revision of manuscript for important intellectual content:

R. Wall Emerson, K. Naghshineh.
Statistical analysis: D. S. Kim, R. Wall Emerson.

Obtained funding: D. S. Kim, R. Wall Emerson.

Study supervision: D. S. Kim.

Financial Disclosures: The authors have declared that no competing interests exist. The VSP system tested in this study is a prototype-level system similar to what is implemented in a production-level Nissan electric vehicle. However, the authors have no declarable financial relationship with Nissan.

Funding/Support: This material was based on work supported by the National Eye Institute, National Institutes of Health (grant 2R01

EY12894-07), and a Vehicle Sound Study grant from Nissan Technical Center North America.

Institutional Review: Upon arrival at the site, each participant signed an informed consent form approved by WMU's Human Subjects Institutional Review Board.

Participant Follow-Up: The authors plan to inform participants of the publication of this study.

Disclaimer: The contents of this article are solely the responsibility of the authors and do not necessarily represent the official views of the National Eye Institute or Nissan Technical Center North America.

\section{REFERENCES}

1. Jacobson WH. The art and science of teaching orientation and mobility to persons with visual impairments. New York (NY): AFB Press; 1993.

2. LaGrow SJ, Weessies MJ. Orientation and mobility: Techniques for independence. Palmerston North (New Zealand): The Dunmore Press; 1994.

3. Gescheider GA. Psychophysics: The fundamentals. 3rd ed. Mahwah (NJ): Lawrence Erlbaum; 1997.

4. Macmillan N, Creelman C. Detection theory: A user's guide. 2nd ed. Mahwah (NJ): Erlbaum; 2004.

5. Moore B. Frequency selectivity. London (UK): Academic Press; 1986.

6. Wiener W, Naghshineh K, Salisbury B, Rozema J. The impact of hybrid vehicles on street crossings. RE:view. 2006;38:65-78. http://dx.doi.org/10.3200/REVU.38.2.65-78.

7. J.D. Power and Associates [Internet]. Westlake Village (CA): Future global market demand for hybrid and battery electric vehicles may be over-hyped: Wild card is China; [updated 2010 Oct 27; cited 2010 Dec 22]. Available from: http://businesscenter.jdpower.com/news/pressrelease.aspx?ID=2010213

8. Kitamura M, Hagiwara Y. Are hybrid cars dangerously quiet? The Seattle Times. 2009 Sep 25. Available from: http://seattletimes.nwsource.com/html/businesstechnology/ 2009922506 quietcars23.html

9. Motavalli J. Hybrid cars may include fake vroom for safety. The New York Times. 2009 Oct 13. Available from: http://www.nytimes.com/2009/10/14/automobiles/ 14hybrid.html

10. Whoriskey P. The deadly silence of the electric car: Automakers propose adding some artificial vroom to alert pedestrians. 
The Washington Post. 2009 Sep 29. Available from: http:// www.mail-archive.com/medianews@etskywarn.net/ msg05678.html

11. Allen W, Barbier A, Griffith A, Kern T, Shaw C. Orientation and mobility teaching manual. 2nd ed. New York (NY): CIL Publications; 1997.

12. Hill E, Ponder P. Orientation and mobility techniques: A guide for the practitioners. New York (NY): AFB Press; 1976.

13. Pogrund R, Healy G, Jones K, Levack N, Martin-Curry S, Martinez C, Marz J, Roberson-Smith B, Vrba A. Teaching age-appropriate purposeful skills: An orientation and mobility curriculum for students with visual impairments. Austin (TX): Texas School for the Blind and Visually Impaired; 1995.

14. Guth D, Hill E, Rieser J. Tests of blind pedestrians' use of traffic sounds for street-crossing alignment. J Vis Impair Blind. 1989;83:461-68.

15. Willoughby D, Monthei S. Modular instruction for independent travel for students who are blind or visually impaired: Preschool through high school. Baltimore (MD): National Federation of the Blind; 1998.

16. Lawson G, Wiener W. Audition for students with vision loss. In: Wiener JE, Welsh, R, Blasch B, editors. Foundations of orientation and mobility. 3rd ed. New York (NY): AFB Press; 2010. p. 84-137.

17. Long RG, Guth DA, Ashmead DH, Wall Emerson RS, Ponchillia PE. Modern roundabouts: Access by pedestrians who are blind. J Vis Impair Blind. 2005;99:611-20.

18. Sauerburger D. Safety awareness for crossing streets with no traffic control. J Vis Impair Blind. 1995;89:423-32.

19. Blake R, Sekuler R. Perception. 5th ed. New York (NY): McGraw-Hill; 2006.

20. Fastl H, Zwicker E. Psycho-acoustics. 3rd ed. Berlin (Germany): Springer; 2007.

21. Goldstein EB. Sensation and perception. 7th ed. Belmont (CA): Thompson Wadsworth; 2007.

22. Moore B. An introduction to the psychology of hearing. 5th ed. Bingley (UK): Emerald Group Publishing; 2008.

23. Palmer AR. Neural signal processing. In: Moore B, editor. Hearing. London (UK): Academic Press; 1995. p. 75-121.

24. LeLong J. Vehicle noise emission: Evaluation of tire/roadand motor-noise contributions. Inter-Noise 99; 1999 Dec 6-8; Fort Lauderdale, FL.

25. Nelson R. Transportation noise reference book. Boston (MA): Butterworths; 1987.

26. Robart R, Rosenblum L. Are hybrid cars too quiet? J Acoust Soc Am. 2009;125:2774.

27. Emerson RW, Naghshineh K, Hapeman J, Wiener W. A pilot study of pedestrians with visual impairments detecting traffic gaps and surges containing hybrid vehicles. Transp Res Part F Traffic Psychol Behav. 2011;14(2):117-27.

\section{[PMID:21379367]}

http://dx.doi.org/10.1016/j.trf.2010.11.007

28. National Highway Traffic Safety Administration (US). Incidence of pedestrian and bicyclist crashes by hybrid electric passenger vehicles. Washington (DC): Department of Transportation (US); 2009. (DOT HS 811 204). Available from: http://www-nrd.nhtsa.dot.gov/Pubs/811204.PDF

29. Green D, Swets J. Signal detection theory and psychophysics. New York (NY): Wiley; 1966.

30. Fletcher H. Auditory patterns. Rev Mod Phys. 1940;12:47-65. http://dx.doi.org/10.1103/RevModPhys.12.47

31. Margolis RH, Dubno JR, Hunt SM. Detection of tones in band-reject noise. J Speech Hear Res. 1981;24(3):336-44. [PMID:7300274]

32. Moore B. Frequency selectivity. London (UK): Academic Press; 1986.

33. Versfeld NJ, Houtsma AJ. Perception of spectral changes in multi-tone complexes. Q J Exp Psychol A. 1991;43(3): 459-79. [PMID:1775652]

http://dx.doi.org/10.1080/14640749108400982

34. Buser P, Imbert M. Audition. London (UK): MIT Press; 1992.

35. Wall Emerson R, Sauerburger D. Detecting approaching vehicles at streets with no traffic control. J Vis Impair Blind. 2008;102(12):747-60. [PMID:20126414]

36. Myers A, Hansen C. Experimental psychology. 6th ed. Belmont (CA): Thomson Wadsworth; 2006.

37. Stein DK. Stop, look, and listen: Quiet vehicles and pedestrian safety. The Braille Monitor. June 2005. Available from: http://www.nfb.org/Images/nfb/Publications/bm/bm05/ bm0506/bm050605.htm

38. Nuckols B. Blind people say hybrids are hazard. The Braille Monitor. November 2007. Available from: http:// www.nfb.org/images/nfb/Publications/bm/bm07/bm0710/ bm071002.htm

39. Cohen J. Statistical power analysis for the behavioral sciences. 2nd ed. Mahwah (NJ): Lawrence Erlbaum; 1988. p. 273-311.

40. Erdfelder E, Faul F, Buchner AG. GPOWER: A general power analysis program. Behav Res Methods Instrum Comput. 1996;28:1-11. http://dx.doi.org/10.3758/BF03203630

41. Keppel G. Design and analysis: A researcher's handbook. 3rd ed. Englewood Cliffs (NJ): Prentice-Hall, Inc; 1991.

42. Neff DL, Callaghan BP. Effective properties of multicomponent simultaneous maskers under conditions of uncertainty. J Acoust Soc Am. 1988;83(5):1833-38. [PMID:3403798] http://dx.doi.org/10.1121/1.396518

43. Neff DL, Green DM. Masking produced by spectral uncertainty with multicomponent maskers. Percept Psychophys. 1987;41(5):409-15. [PMID:3601622]

http://dx.doi.org/10.3758/BF03203033

44. Neff DL, Jesteadt W. Intensity discrimination in the presence of random-frequency, multicomponent maskers and broadband noise. J Acoust Soc Am. 1996;100(4 Pt 1): 
2289-98. [PMID:8865636]

http://dx.doi.org/10.1121/1.417938

Submitted March 9, 2011. Accepted in revised form September 28, 2011.

This article and any supplementary material should be cited as follows:

Kim DS, Wall Emerson R, Naghshineh K, Pliskow J,
Myers K. Impact of adding artificially generated alert sound to hybrid electric vehicles on their detectability by pedestrians who are blind. J Rehabil Res Dev. 2012; 43(3):381-94.

http://dx.doi.org/10.1682/JRRD.2011.03.0041

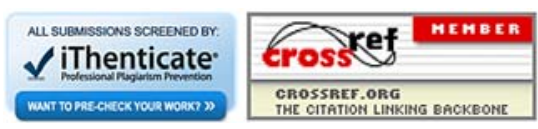


